\title{
Natural Commercial Centres: Regeneration Opportunities and Urban Challenges
}

\author{
Gabriella Esposito De Vita ${ }^{1, a}$, Stefania Ragozino ${ }^{1, b}$ \\ ${ }^{1}$ Institute for Service Industry Research of National Research Council, Naples, Italy \\ ag.esposito@irat.cnr.it, bs.ragozino@irat.cnr.it
}

Keywords: SME Retail, Natural Commercial Centre, Urban Regeneration.

\begin{abstract}
In the history of European cities, public spaces always played a pivotal role, representing key places for developing social interactions and for enhancing the sense of community. Squares, commercial streets, market places as well as traditional retail and art-and-crafts areas can be considered the core of the city. The social, economic and demographic crisis and the loss of cultural identity has affected the capacity of attraction of local small retailers, giving the floor to aggressive strategies such as suburban shopping malls, centres, arcades or precinct, forming a complex of shops, movie theatres, restaurants and food courts with interconnecting walkways [1]. Typical expressions of a globalized economy, the different categories of suburban shopping mall have transformed behaviours and paths at a large scale [2]. One of the consequences can be identified in the loss of traditional commercial activities within the city centre, producing a situation of urban decline, mirrored by the impoverishment of public spaces $[3,4,5,6,7]$. This paper suggests that, by activating the existing cultural and socio-economic capital, it is possible to undertake a successful regeneration process based on a participative approach and on public and private integrated tools. By focussing on the experience of the Centri Commerciali Naturali (natural malls) - established in Italy as partnership between Municipalities, cultural operators, public services providers and associations of shops owners to exploit the commercial activities in the historical centres - the ongoing research is oriented to explore successful experiences of private-public partnership to be implemented in a regeneration process of areas traditionally dedicated to retail and art-and-craft small enterprises. The paper discusses the potentiality and the criticism of the Centri Commerciali Naturali as engine for the redevelopment and regeneration of the inner city abandoned retail areas. In so doing, the experience developed in Campania (Southern Italy) will be analysed in order to show how the activation of the social capital within the framework of the Centri Commerciali Naturali could contribute in renovating the traditional commercial identity of the area, supporting the public spaces regeneration process. This paper aspires to offer useful insights to all those policy makers, city managers and planners who seek to revitalise traditional market areas in European city centres.
\end{abstract}

\section{Issues and criticism embedded in the loss of traditional retail areas in the city centres}

In the European city, retail activities in public space have been the engine of local identity for centuries. Still in recent time, Jane Jacobs [8] highlighted the role of traditional retails in maintaining the identity of a neighbourhood, while the urban sociologist Oldenburg [9] explained the importance of "good places" in allowing socialisation within the city. Nowadays, many urban design codes explicitly require city centre blocks to provide active ground floor edges to the street, also for safety matters - in order to ensure social control on the streets. The mutual influence among traditional retails, public spaces and social life suggests that a comprehensive approach is recommended, and that regeneration initiatives which include traditional market areas should pay great attention both to the physical quality of the urban design and to the valorisation of social networks embedded in the commercial activities. Many cities are plagued by a decrease in the number of commercial activities within the city centre, also due to the development of suburban commercial areas that offer cheapest location and attract globalised competitors $[4,5,6]$. 
The long historical and cultural tradition of European cities reveals the importance of public space and the role of retailing in the enhancement of historical centres [10]. The market areas have typically been considered the key places for social interaction and development of urban communities [11], as well as the morphology of European cities over the centuries has been influenced by local patterns of commercial development [11, 12] [8]. Therefore, the healthy condition of those districts reflects the image of the neighbourhood and the city [13]. Both the economic crisis and the loss of cultural heritage has resulted in a spatial reorganization and alignment with the new technologies [14], and this has affected the historical centres of European cities: the natural malls - result of the slow sedimentation of productive and commercial activities - have been abandoned or transformed in open-air museums as background and scenario for the exhibitions of the global market firms [15]. This phenomenon feeds imbalances and conflicts [16] visible in the signs of urban decline [17, 18]. At the same time, we can observe the development of numerous sanctuaries of the prominent commercial firms in which the values of public space are often lost [18]. Both logistic issues and globalization trends have determined the economic success of the suburban commercial areas, offering the opportunity of producing the critical mass for maximizing the revenues and for dealing with the increasing of e-commerce and other smart ways of interpreting dreams and needs [2].

This paper focuses on the progressive impoverishment of public places traditionally dedicated to commercial activities in the inner city - due to a complex combination of factors such as the spread of suburban shopping and leisure centres and of the e-commerce experiences - discussing possible strategies and partnerships for addressing these phenomena in an innovative way. In so doing it discusses the Centri Commerciali Naturali, introduced by law in Italy (Campania Regional Law 1/09) and established in several urban areas nationwide through an agreement between municipalities and retail owners. This approach, which can be considered the Italian way to the Town Centre Management schemes [19], has been developed in order to deal with the progressive abandonment of former catalyst retail areas in the consolidated city by introducing a new form of public-private partnership able to support regeneration processes centred on the preservation of a vibrant mixitè of activities and uses [20]. The paper suggests that the socio-economic capital activation can contribute to undertake successful regeneration processes based on a participative approach and on public and private integrated tools. The renewed forms of cooperation between economic and social subjects (i.e. retailers, artisans, tourism operators, social workers, public services, professional firms and other business) and public institutions aim at providing incentives for revitalizing significant areas in terms of cultural identity, with the added value of job creation and local redevelopment [1].

The empowerment of local communities as strategy for better regeneration policies [21] is supported by referring to planning documents and case studies. The Italian planning culture in the '90s, with the integrated programs tools [22], has been characterized by experiences of regeneration oriented to incorporating participation and identity in the production of values for the territory [23]. The European forthcoming programming period 2014-2020 identifies the community-led place-based initiatives as key players in the delivery of the European expenditure. This trend stems on the experience of the Local Action Plans developed within the framework of European projects such as the URBAN and URBACT initiatives on how to integrate socio-economic and physical actions on urban target areas characterized by both a strong local identity and problems of deprivation and decay. The main aims of these experiences can be considered to promote job creation and to revitalize the neighbourhood economy. The impact of these initiatives is testified by several cases in Europe [24].

These experiences show how community empowerment, also through community led specific initiatives, can contribute to achieve regeneration goals, specifically in the current context of reduced public expenditure. According to this scenario, the survey of tools and initiatives oriented to deal with the progressive deprivation of areas of the inner city - characterized by a strong local tradition of small art and crafts enterprises - has been developed by promoting an intense social activation. At this purpose, the paper first discusses the role of traditional urban retail and artisanal areas in enhancing regeneration processes by preserving local identity and culture, advocating the recasting of local development issues within a more communitarian oriented conceptual frame. Selected initiatives 
developed in the USA have been analyzed in order to understand issues and potentiality in addressing the integration of typical handicrafts, dense residential uses, traditional commercial activities and the historical character of public places dedicated to identitarian artisanal and commercial activities that have been partially abandoned due to the societal transformations. Secondly, the research explores this nexus as interpreted in Italy by promoting the Natural Commercial Centres. Findings and conclusions are oriented to highlighting possible takeaways for practice and future research lines.

\section{Inspiring partnerships tools for promoting regeneration processes: experiences in the USA}

The main challenge in establishing effective partnership tool for urban regeneration is represented by the protection and revitalization of vibrant public spaces or public use characterized by a historical tabernizzazione and a commercial vocation and leisure that strongly characterize the local identity and representing a heritage to be treasured. The risk of losing those values that have made the European city the eligible place for liveability - the human scale and the open and inclusive cultural identity - has been exacerbated due to the current crisis scenario. These trends leading to focus on some underestimated assets that lagged behind in opulent times, such as the added value potentially embedded in urban social networks, the so-called civic economics [25]. According to this concept, this paper seeks to unveil the nexus between urban regeneration and the preservation of places and activities related to artisanal and retail local traditions, by investigating the community-based partnership schemes as inspired by the experiences developed in USA in the last decades.

Referring to the USA context, where the discussed phenomena started earlier, we can appreciate two important elements: first, the issues related to the suburbanization of the retail and leisure activities can be addressed in its wider form; secondly, trends could be anticipated and strategies could be understood by observing this mature scenario. In the U.S.A. scenario, we could be inspired by strategies and policies developed abroad in identifying informal place management schemes or hybrid partnerships which could be effective in delivering positive outcomes for urban communities [20:74]. In order to develop and maintain the traditional commercial areas in the city centre, is important to have strong management leaders, urban critical mass and the capacity of building a shared consensus in order to deal with the regeneration issues [26]. The general theory of neighbourhood regeneration is paramount to merge public, private and non-profit sectors [13] in order to improve a durable development based on the job creation and the credit distribution [27], [13].

Complex partnerships have been analyzed by their funding sources and structural formality using a case study approach under the umbrella of the Commercial Local Urban Districts (CLUDs) rationale as interpreted within the framework of the CNR IRAT project Urban Regeneration Tools for Re-branding Natural Commercial Districts [28, 29]. Different typologies of public-private partnerships have been identified and different case studies have been analyzed in challenging the market oriented vision of the globalized economy - dominating until the $80 \mathrm{~s}$ in urban renewal initiatives overseas - by introducing a more communitarian oriented approach to the economics [30]. In so doing, the research is dealing with rigidly structured experiences, such as the Business Improvement Districts, informal or hybrid bottom up initiatives, as in the case of the Community Development Corporations, rural-urban linkages developed through farmer markets networks, as well as experiences based on the preservation of historical and cultural heritage, such as the Main Street Program initiatives, based on the conservation of values, morphologies, human scale and vibrant public spaces of the traditional commercial areas [31].

Each category of partnership has been analyzed in terms of the added value of community and local stakeholders engagement in promoting, developing and managing regeneration processes. The role of community engagement in urban regeneration policies - lacking public-led initiatives in the field has been recognized in the United States in the early 1990s, as the Clinton administration fostered a clearly community empowerment led approach to urban regeneration, pursued through the Empowerment Zones. This initiative "required unprecedented level of participation by community" [32]. Typical expression of this trend are charitable organizations called Community Development 
Corporations, non-profit corporation serving an area "that is economically disadvantaged" [32]. The importance of Community Development Corporations in contemporary urban regeneration is testified by their success all around the States. A best practice in this area could be considered the experience of the Jamaica Plain Neighbourhood Development Corporation in Boston - symbolic case of Community Development Corporation based on industrial archaeology, place-based retail, green economy and community facilities [33].

These and other experiences in U.S.A. might appear naive when compared with the complex layering of the European cities. But the spirit of these initiatives and their contexts - which could be a foretaste of what is going to happen in Europe - could be inspirational for the discussion on how to promote and support social activation and public-private initiatives in contexts of crisis. According to this scenario, a focus on the experience of the natural malls schemes has been developed in order to address issues and potentiality of the different combinations of funding sources and structural formality for retail-led regeneration processes in the Italian context.

\section{The initiative of the Centri Commerciali Naturali in Campania: new perspectives and criticisms}

The experience of the Region of Campania in Italy can be considered relevant in dealing with the abandonment and decay of historical market places in the inner city due to the wide spread of suburban malls and the transformation of behaviours and profiles of users and consumers. The Campania Government has approved a law and a specific budget to promote natural mall which could be defined the Italian way to the Anglo-Saxon experience of the Town Centre Management.

Table 1: Natural Commercial Centres in the Region of Campania

\begin{tabular}{|c|c|c|c|c|}
\hline Provinces & Natural Commercial Centres & Owners & $\begin{array}{l}\text { Economic } \\
\text { resources }\end{array}$ & Pictures \\
\hline \multirow{8}{*}{ Naples } & Antico Borgo Orefici & 75 & $€ 200,000.00$ & \multirow{14}{*}{ 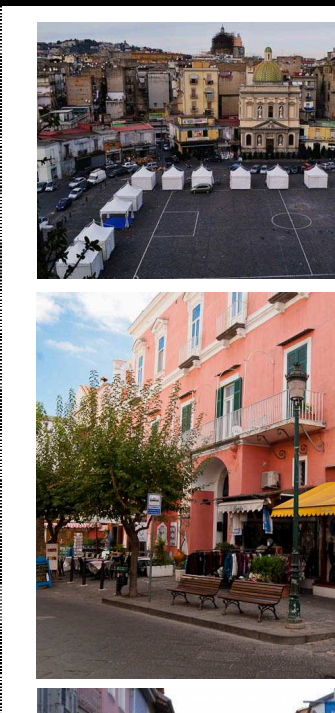 } \\
\hline & $\begin{array}{l}\text { Consorzio Antiche Botteghe } \\
\text { Tessili }\end{array}$ & 25 & $€ 200,000.00$ & \\
\hline & Consorzio Infiniti & 80 & $€ 200,000.00$ & \\
\hline & Epomeo dal 1985 & 750 & - & \\
\hline & Consorzio Borgo Ischia Ponte & 35 & - & \\
\hline & Venuti Panoramica & 20 & - & \\
\hline & Terrenziano & - & - & \\
\hline & Borgo Partenope & 25 & $€ 610,296.08$ & \\
\hline \multirow{6}{*}{ Caserta } & Le Botteghe del Centro & 120 & $€ 200,000.00$ & \\
\hline & Consorzio Piazza Umberto I & - & $€ 172,500.00$ & \\
\hline & Il Basilisco Borgo Normanno & 29 & $€ 308,453.00$ & \\
\hline & Normanno Aversa Città & - & $€ 76,211.50$ & \\
\hline & Capua Arte e Cultura & & - & \\
\hline & Consorzio Alife & 40 & $€ 99,817.75$ & \\
\hline \multirow{2}{*}{ Avellino } & Lionincentro & 104 & $€ 55,375.50$ & \\
\hline & Ariano Centro Storico & 101 & $€ 483,225.64$ & \\
\hline \multirow{3}{*}{ Salerno } & Facciamo Centro & - & $€ 120,000.00$ & \\
\hline & 20.10 & - & - & \\
\hline & Cava & 17 & $€ 677,997.15$ & \\
\hline
\end{tabular}

The idea of promoting natural malls, the so called Centri Commerciali Naturali starts, being discussed in Italy since the late '90s with the goal of transferring tools and schemes of Town Centre Management in the regeneration processes in declined city centres. In particular, according to the Campania Regional Law 1/09, the Region of Campania needs to promote processes of aggregation and enhancement of small business enterprises and art and craft initiatives through the establishment of natural malls in order to boost traditional and identitarian retail activities in the historical centres. 
The Resolution No. 160 of the Campania Regional Council (approved on June 3, 2013) has defined the characteristic needed for the establishment of the natural malls and the related funding.

The Centri Commerciali Naturali have been established "to promote the retail-led initiatives in order to favour the redevelopment of historical urban centres, by promoting processes of aggregation and enhancement of commercial and artisanal small businesses under the umbrella of natural malls" (Regional Law 1/09). In particular, this kind of natural mall should be: "the aggregation, at neighbourhood level, of small enterprises, medium-size facilities, public services, art and craft initiatives as well as tourism providers which have been developed spontaneously in homogeneous urban areas, recognizable because of their own autonomous organizational structure; these integrated entities need to promote the critical mass for enhancing the customers demand, for optimizing services and supplies, for innovating the supply chains as well as for developing a shared revitalization of the area" (Regional Law 1/09). The Centri Commerciali Naturali could be thematic if the offer is related to a specific category of goods and services or could be territorial if the character is related to local traditions or productions, both oriented at promoting the partnerships for the local development and the attractiveness of the retail and tourist areas. Each natural mall has the following aims: organizing a local system of integrated supplies for manufacturing, retail and tourism initiatives; branding or re-branding the area according to the local traditions and cultural resources; promoting research and innovation in the field and the dissemination of initiatives; implementing joint programs of retail, cultural initiatives and tourism; providing services to the members; managing accessibility and uses of public spaces in order to favour urban re-development and regeneration. The critical mass to create a non-profit consortium for establishing a natural mall starts from 25 units (Thematic) and from 40 units (Territorial).

In order to appreciate the trends, the schemes of partnerships and the funding possibilities for developing a regeneration process according to the founding principles of the Centro Commerciale Naturale, a case study approach has been developed in Campania. According to the research methodology developed in the USA within the framework of the CLUDs rationale, a purposely selected study area has been analysed with a case study approach [34]: the historical marketplace of Piazza Mercato in Naples (Italy) and the surroundings, characterized by a strong retail and artisanal tradition. The historic marketplace and the goldsmith and textile districts, included in the historical centre of Naples have been selected due to the official establishment of the Centro Commerciale Naturale Consortium and the coexistence of different typologies of bottom up and top down processes of refurbishment and redevelopment. Another important element as been identified in order to better appreciate the complex web of economic trends, customers behaviours, logistic needs and cultural heritage: the relationships between abandonment and decline of the area and the opening of the bigger wholesale centre, the so called Centro Ingrosso Sviluppo (CIS), in the metropolitan area.

In order to achieve a comprehensive view of the current scenario of the historical market area of Naples and the related thematic retail clusters, the two commercial polarities - the one in the inner city and the one located in the suburbs - have been analyzed together by identifying the main events that have occurred in defining the current structures and the current flows of people, goods and resources. The first step of the ongoing research process has been the definition of the following time line depicting the events that, in a synergistic way, have defined the development of both the areas (Fig. 1).

The Centro Ingrosso Sviluppo, opened in 1986 in Nola within the metropolitan area of Naples, can be considered one of the greatest non-food centre in Southern Europe and the catalyst of the migration phenomenon of productive activities from the area of Piazza Mercato. In the early 90s, small enterprises, artisans and retailers, due to logistic supplies and the support services provided, have chosen to transfer their activities from the inner city to the new suburban commercial hub. Around the 2000 the wholesale mall was enlarged and integrated with other nodes such as the Tari - dedicated to the Goldsmith enterprises - and the intermodal logistic hub named Interporto. The complexity of the multilayer relationships among those areas needs to be investigated by using a complex approach. Nevertheless, cause-effect relationships could be addressed by collecting quantitative data trends related to the enterprises operating in both the areas: number of employees, opening and abandonment 
of recorded enterprises, number and surfaces of shops, financial balance sheets. The first set of data collected provides evidences of a progressive decline between 1981 and 2001 of the enterprises in the inner city, coupled with increasing of the suburban pole. At the edge of 2000 the decline of the historical commercial district of Piazza Mercato was relevant, producing effects on the quality of the everyday life: abandonment and decay of public spaces, loss of vitality of the area, high perception of insecurity.

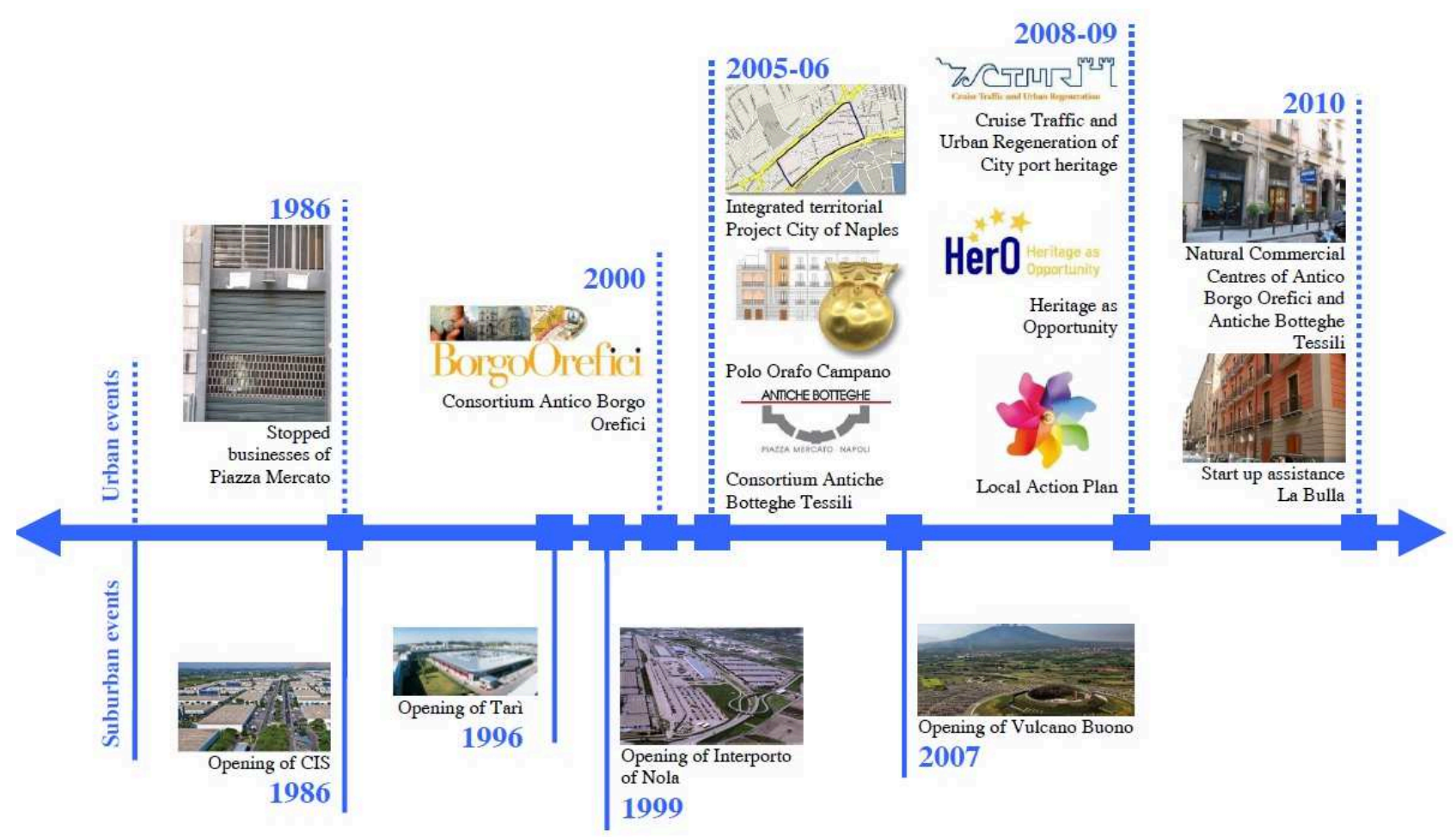

Figure 1: Time line

The artisanal and retail tradition was challenged and the risk of the loss of the original cultural heritage was high; in order to deal with this trend the entrepreneurs, the local authorities, the activists and part of the local communities decided to start cooperating for developing integrated actions. The first spontaneous private partnerships have been built for the preservation of the cultural traditions related to the textile and goldsmith production and sale: the Consortium Antico Borgo Orefici (2000) and the Consortium Antiche Botteghe Tessili (2006) were established in order to start an integrated process of community-led urban regeneration [35]. The initiatives supported by the consortia could be considered the engine for the different typologies of initiatives which concur in the area. According to this, the European-funded integrated project for Naples developed by the City Council within the framework of the Regional Operative Programme (2005-2008, $€ 3,555,000)$, has been dedicated to the refurbishment and requalification of public places in the area.

Both the consortia, in cooperation with other minor enterprises and local community associations, need to enhancing the civic participation to the regeneration process on the one hand and, on the other, need stimulating the public participation and co-funding for dealing with the gentrification process and the general decline of the inner city. While the suburban pole of the Centro Ingrosso Sviluppo -Interporto has been enriched with the new signature shopping mall Vulcano Buono (2007) designed by Renzo Piano - reinforcing the territorial hub in Nola, the civic activation in the historical market place is operating by attracting resources and attention through the URBACT projects managed by the City of Naples. Synergies among social and economic stakeholders, local administrations and international networks have produced a sort of compensation against the loss of critical mass in the studied area. Thanks to the European projects, funded within the framework of the URBACT initiatives, "Heritage as Opportunity" and "Cruise Traffic and Urban Regeneration of City Port 
Heritage" a Local Action Plan have been developed [24] by promoting a Local Support Group oriented to deal with integration of the historical market place in the cultural, touristic and maritime systems of Naples. The last steps of this complex and articulated process have been the establishment (2010) of the Business Incubator La Bulla in a building owned by the City within the historical complex of Sant'Eligio, in order to favouring start ups and other initiatives for job creation and urban regeneration. In the same year the natural mall in the area has been constituted and partially funded by the Campania Regional Law n. 1/2009 (Tab. 1).

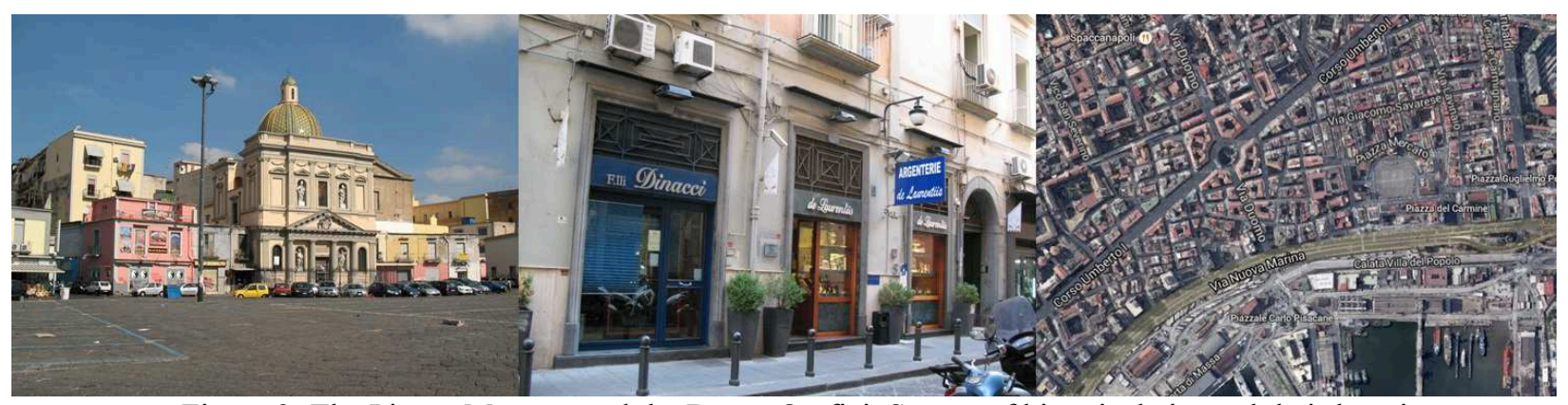

Figure 2: The Piazza Mercato and the Borgo Orefici. Spaces of historical city and their location.

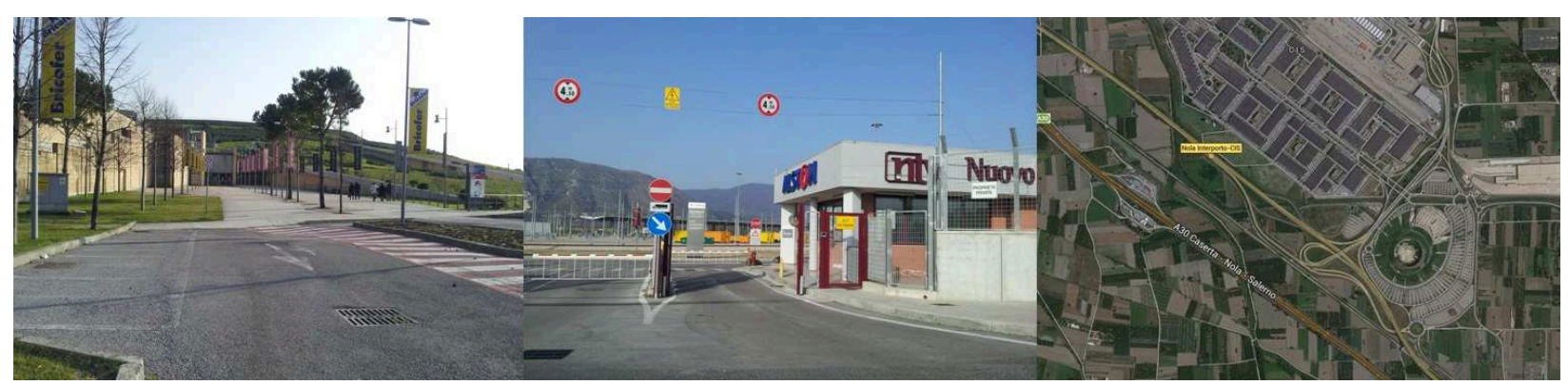

Figure 3: Entrances of the Vulcano Buono and Interporto Campano. Spaces of suburban city and their location.

The process described supports us in interpreting the current scenario and the impact of the Centro Commerciale Naturale on the local regeneration processes and on the urban-suburban linkages related to the commercial activities. The fieldwork has been developed by interpreting the context through data collection, active observation, participation in public initiatives, charrettes and events as well as visual analysis and interviews. Dedicated survey forms have been defined in order to combine direct and indirect analysis with quantitative and qualitative information from different sources. After developing the context analysis and trends, a consultation phase has been opened, administering semi-structured interviews to the key stakeholders operating in the study area (Tab. 2). The interviews scheme has been purposely built in order to address the issues related to the natural mall establishment: participation in the initiatives, perception of security, quality of public places, availability of services and supplies, criticism and opportunities, regeneration priorities. The one-hour interviews have been recorded following the research protocol and interpreted according to the findings of the analysis of the built environment, the cultural heritage and customer behaviours in the area.

Table 2: Classification of interviews

\begin{tabular}{lcl}
\hline Sector & Number of interviews & Interest level \\
\hline Safety and security issues & 11 & National, metropolitan, local district \\
Data collection and management & 2 & Local district, city wide \\
Territorial & 10 & Metropolitan, city wide \\
University & 9 & Local district \\
Groups, companies, associations & 19 & Local district, city wide \\
TOTAL & 51 & \\
\hline
\end{tabular}


The findings of the first phase of the research can be summarized in the following points:

- There are complex relationships between the abandonment of the historical marketplace of Piazza Mercato and the development of the suburban commercial hub of Centro Ingrosso Sviluppo -Interporto-Vulcano Buono which need to be analysed in depth in order to identify the possibilities in terms of mutual influence and cooperation for dealing with the economic crisis.

- New forms of solidarity, networking, mutual support and social activation in areas challenged by societal and economic crises could be more effective in context characterized by ingrained traditions and attitudes such as the textile and goldsmith art and craft production and sale.

- The establishment of the natural mall has been important in achieving the critical mass of human, cultural and economic resources in order to facilitate the activation of integrated actions and to optimize investment and results.

- Since the establishment of the Centro Commerciale Naturale, four years ago, cultural experiences, exploitation events, security enhancement programmes and marketing initiatives have been accomplished; nevertheless, a vibrant development could not being still appreciated and the needed integration of the regeneration processes is still a wish.

- The scheme of the public private partnership implemented in the current natural mall experiences needs to be adapted to the transformed conditions and limits, in order to make it consistent with the globalization dynamics and the acceleration of processes.

\section{Conclusions and takeaways for practice}

The experience of Centro Commerciale Naturale in Campania, although very promising, is still an empty box because the experiments undertaken have not yet experienced a real boost to the redevelopment and urban regeneration. The local consortia of place-based enterprises have been engines of a positive civic activation and have played a pivotal role in re-branding the area, according to the cultural traditions. Nevertheless, there is a lack of structural long-term results: the cooperation between stakeholders needs more continuity, the bureaucracy curbs enthusiasms and initiatives and the scarce political stability reduces the positive impact of investments. Although the strong identity of the area, the cultural heritage and the density of traditional artisanal productions could be considered the engine for developing integrated regeneration initiatives, a critical mass of human, cultural and economic resources is needed in order to activate an integrated and exhaustive regeneration process, optimizing investment and results. In so doing, renewed public-private partnership schemes for urban regeneration purposes need to be adapted to the specific contexts in order to favour the participation, the investment and the positive effects on territory as a whole.

The ongoing research aims at interpreting the experiences of Centro Commerciale Naturale, combining qualitative and quantitative approaches, in order to indentify criticisms and opportunities of this tool and to re-define the appropriate public-private partnership schemes. According to the inspirational platform performed within the framework of the CLUDs project, an integrated survey model has been developed in order to capture the partnerships schemes and to promote their effectiveness in different contexts. The strategies and policies developed overseas have been analysed in order to identifying informal place management schemes or hybrid partnerships which could be merged within dynamic public-private partnership models to be implemented successfully in Italy. The bottom up initiatives needs to be facilitated by flexible and dynamic partnerships and accompanied through funding schemes and bureaucratic paths in order to support creativity and enthusiasm of communities and operators in being effective and consolidating the results on the long term.

\section{Acknowledgements}

This work has been developed within the framework of Marie Curie IRSES Project CLUDs in cooperation with the IRAT CNR project "Urban regeneration tools for re-branding natural commercial districts". 


\section{References}

[1] R. Paparelli and M. Del Duca: Centri commerciali naturali. Strategia e strumenti di network marketing a servizio del commercio, del turismo e del terziario. Milano: Franco Angeli (2010)

[2] F. D. Moccia and A. Sgobbo: La polarizzazione metropolitana. L'evoluzione della rete della grande distribuzione verso un sistema policentrico sostenibile. Napoli: Liguori Editore (2013)

[3] S. Zukin: The Cultures of Cities. Oxford: Basil Blackwell (1995)

[4] A. Loukaitou-Sideris: Revisiting inner-city strips: A framework for community and economic development, Econ. Dev. Q., vol. 14, no. 2, (2000), pp. 165-181

[5] S. Halebsky: Superstores and the politics of retail development, City Community, vol. 3, no. 2, pp. 115-134, 2004.

[6] M. Lowe: The regional shopping centre in the inner city: a study of retail-led urban regeneration, Urban Stud., vol. 42, no. 3, (2005), pp. 449-470

[7] M. Sansone: Confronti metodologici, riflessioni critiche e proposte operative sul Marketing Urbano in ambito internazionale: focus sull'organizzazione e gestione dei Centri Commerciali Naturali in Italia, in Marketing Trends, 2007, vol. 58, no. (1996), pp. 26-27

[8] J. Jacobs: The Death and Life of Great American Cities, vol. 71. (1961), p. 458

[9] R. Oldenburg: The great good place: Cafés, coffee shops, community centers, beauty parlors, general stores, bars, hangouts, and how they get you through the day. New York: Paragon House, (1989)

[10] L. Zanderighi: Town Centre Management: uno strumento innovativo per la valorizzazione del centro storico e del commercio urbano, Ind. Distrib., no. 2, (2001)

[11] S. Carr, M. Francis, L. G. Rivlin, and A. M. Stone: Needs in public space, in Public Space, Cambridge: Cambridge University Press (1992)

[12] G. Esposito De Vita, C. Trillo, and S. Oppido: Rigenerazione degli spazi pubblici e centri commerciali naturali: il caso di Piazza Mercato e Borgo Orefici a Napoli, Planum, no. 26, (2013)

[13] K. Seidman: Inner-city commercial revitalization: A literature review, Boston (2004)

[14] B. Secchi: Un’urbanistica di spazi aperti, Casabella, vol. 597, no. 598, (1993), p. 5

[15] "National Institute for Distribution and Services." [Online]. Information on http://www.indisunioncamere.it/

[16] M. Cremaschi: Sul disagio urbano, Arch. di Stud. urbani e Reg.,(2001)

[17] K. Chapple and R. Jacobus: Retail trade as a route to neighborhood revitalization, Urban Reg. policy its Eff., vol. 2, (2009), pp. 19-68

[18] S. A. Sutton: Rethinking commercial revitalization: A neighborhood small business perspective, Econ. Dev. Q., vol. 24, no. 4, (2010), pp. 352-371

[19] J. A. Coca-Stefaniak, C. Parker, S. Quin, R. Rinaldi, and J. Byrom: Town centre management models: A European perspective, Cities, vol. 26, no. 2, (2009), pp. 74-80 
[20] M. Ricci and P. Valentino: A focus on CCN in Italy: an integrated approach among urban renewal and PPP, in FIRST SCIENTIFIC REPORT 2012 CLUDs PROJECT - Economic Development Strategies. The role of Public Private Partnership, (2012)

[21] R. Atkinson: Addressing urban social exclusion through community involvement in urban regeneration, in Urban Renaissance? New Labour, Community and Urban Policy, Bristol: Policy Press, (2003), pp. 101-119.

[22] P. Avarello and M. Ricci: edited by, Politiche urbane: dai programmi complessi alle politiche integrate di sviluppo urbano, INU. Roma: INU (2000)

[23] A. Magnaghi: Il progetto locale. Torino: Bollati Boringhieri (2000)

[24] Information on http://urbact.eu/

[25] S. Zamagni: L'economia del bene comune, vol. 3. Città nuova (2007)

[26] D. J. Wright: It takes a neighbourhood: Strategies to prevent urban decline. Rockefeller Institute (2001)

[27] A. W. Dyer: Credit access and urban regeneration in the United States, in FIRST SCIENTIFIC REPORT 2012 CLUDs PROJECT - Economic Development Strategies. The role of Public Private Partnership, (2012)

[28] Information on http://www.cluds-7fp.unirc.it/

[29] Network CLUDs, "FIRST SCIENTIFIC REPORT 2012 CLUDs PROJECT - Economic Development Strategies. The role of Public Private Partnership," 2012

[30] A. Etzioni: The new golden rule: Community and morality in a democratic society. Basic Books (1996)

[31] B. Secchi: Prima lezione di urbanistica. Roma: Laterza (2002)

[32] J. B. Cullingworth: British land-use planning: a failure to cope with change?, Urban Stud., vol. 34, no. 5-6, (1997), pp. 945-960

[33] G. Esposito De Vita, C. Trillo, C. Bevilacqua, and A. L. Schultz: Boosting the link between enterprises promotion and heritage valorisation: towards an integrated approach to urban regeneration and tourism development, in Competition and innovation in tourism:new challenges in an uncertain environment, A. Morvillo, edited by, Napoli: Enzo Albano Editore, (2012), pp. 563-584.

[34] R. K. Yin: Case study research: Design and methods, vol. 5. Londra: Sage (2009)

[35] G. Esposito De Vita, C. Bevilacqua, and C. Trillo: Improving Conviviality in Public Places: the case of Naples, Italy," J. Civ. Eng. Archit., vol. 7, (2013), pp. 1209-1219 